\title{
“What Is Wrong With Me?” - Single Women's Reflections on Missing the Marriage Transition
}

\author{
Rozita Ibrahim ${ }^{1}$ \\ ${ }^{1}$ Centre for Liberal Education (Pusat Citra Universiti), Universiti Kebangsaan Malaysia, Malaysia \\ Correspondence: Rozita Ibrahim, Centre for Liberal Education (Pusat Citra Universiti), Universiti Kebangsaan \\ Malaysia, 43600 Bangi, Selangor, Malaysia. Tel: 60-13-210-1331. E-mail: eta@ukm.edu.my
}

Received: November 10, 2015

Accepted: December 1, $2015 \quad$ Online Published: November 16, 2016

doi:10.5539/ass.v12n12p213

URL: http://dx.doi.org/10.5539/ass.v12n12p213

\begin{abstract}
This paper is based on a research about the experiences of singlehood amongst Malay Muslim women in Malaysia. In this paper 'single' refers to never-married women past the normal marriageable age or better known as 'andartu' in the Malay language. The word 'andartu' has similar connotation as 'spinster' in the English language and it indicates failure or a mark of shame. Being a collective society, Malay women's identities are defined within familial roles - first as daughters and later as wives and mothers. As a member of the Malay society, women are expected to follow the societal norms of being married after certain age and having children of their own. This way of perceiving women's roles leave singles at a marginal position and they are deemed as inadequate or incomplete. In relating their experiences of singleness, some women are affected by these negative perceptions. This paper presents case studies of never married women over 30 years old, who asked 'what is wrong with me?'. The paper aims (1) to understand the concerns of these women who pose the question of 'what is wrong with me?' and (2) to examine how these women deal with their feelings of inadequacy. The findings suggest that single women's feelings of inadequacy are related to three major factors which are (1) inability to form a relationship that ends in marriage, (2) not having children of their own, and (3) having lower social status as compared to married women. However these women have their ways of dealing with their feelings of inadequacy by having close relationships with friends and family members, not giving up hope on marriage, committed towards self-improvement, and developing their identities as professional career women.
\end{abstract}

Keywords: gender, singleness, single professional women, marriage, role-identity

\section{Introduction}

This paper discusses the dilemma of single women who are successful in their professions but feel incomplete as women due to their unmarried status. The term 'single' refers to a heterogenous group consisting of the never married and ever married (i.e. divorced, separated and widowed). Thus, different researchers define 'single woman' differently according to the objectives of their studies. In the context of this paper, a 'single woman' is defined as never married and over 30 years old. Generally speaking, though contemporary single women might have developed strategies in dealing with stigma and marginalisation, being single is still regarded as a discreditable status in comparison to marriage (De Paolo, 2006; Holden, 2007; Reynolds, 2008). This is the fact in the present-day even if women are already joining the economic sectors and women's roles are not only confined to the domestic realm. Trimberger (2005: xiii) notes this rightfully in her study on 'The New Single Woman':

I did not find primarily contented single women. Most of them were more conflicted than I was about being single, even though they were not isolated and were leading active, productive lives. Most had strong family ties and/or supportive networks of friends. But it struck me that the new cultural norm of looking for a soul mate, and then becoming an egalitarian couple combining family and work - norms advocated by second-wave feminism - seemed to be taking a heavier toll on the self-confidence of single women today than the older ideal - that a career and conventional family life do not mix for women. Almost all of the women, even those in their fifties, whether heterosexual, lesbian, or bisexual, still hoped to find the 'right one'.

I quoted the above in length because Trimberger's statement bears similarities with my own findings on the experiences of single Malay Muslim women in Malaysia (Note 1). As mentioned above, with 'single' I refer to 
the never married women past normal marriageable age. In Malaysia, the average age at first marriage for female is 23.5 while for male is 26.6 (Center for Reproductive Rights, Asian-Pacific Resource and Research Center for Women, 2005). According to Tey Nai Peng (2007), the percentage of never married women over 30 years old was only $8 \%$ in 1970; but the percentage has increased to $28 \%$ in 2000 . The reasons for the increase are mainly related to women's educational achievement and involvement in the labour force.

Never married women past normal marriageable age are known as 'andartu'(Note 2) in the Malay language. The word 'andartu' has similar connotation as 'spinster' in the English language and it indicates failure or mark of shame. Being a collective society, Malay women's identities are defined within familial roles - first as daughters and later as wives and mothers. This is in line with the argument of role-identity model suggested by McCall and Simmons (1978). According to this model, one's identity is determined by her position as a member of a culture and that identity is not merely for one's own consumption but also determined by other people in day-to-day interactions. Following this, as a member of the Malay culture, women are expected to follow the societal norms of being married after certain age and have children of their own. This way of perceiving women's roles leave singles at a marginal position and are often deemed as inadequate or incomplete. In this paper, I discuss three case studies of women who shared their stories about being inadequate or incomplete by asking the question "what is wrong with me?". These three women are among 30 single never married women who participated in my study on singlehood experiences among Malay Muslim women over 30 years old in Malaysia. The three women were selected because they willingly shared their feelings and thoughts on inadequacy of being single women. In fact, a number of other participants did mention about feeling inadequate and asking the question of "what is wrong with me?" at some points in their lives, but they did not elaborate in detail about their thoughts and feelings during our interview sessions. Thus, the aim of this paper is to unravel the stories of three women who asked the question "what is wrong with me?" and how they deal with the thought of inadequacy and incompleteness as single women. I wish to emphasise here that the stories of these women cannot be generalised to all single women as many of them live singleness differently according to their own unique background and different social environment, as well as being at different points of their lives (Saili, 2012; Azmawati et al., 2015). In this regard I argue that singleness is a dynamic process in which singles define and re-define their identities. As such, the discussion in this paper is only confined to those women who feel that 'something is wrong' with them during the time when I interviewed them. In order to understand their perspective it is essential to discuss the centrality of marriage and why singleness matters to the Malays.

\section{Why Singleness Matters?}

Roziah Omar (1994) in her study describes the ideal Malay woman as (1) being a good Muslim who perform her religious duties such as five daily prayers and fasting in the month of Ramadhan; (2) having inner beauty by being modest as well as having outer beauty by being well-groomed and attractive; (3) able to reproduce and bear the next generation. All these ideals fit the notion of femininity for Malay women and are seen as crucial for them in fulfilling their roles as wives and mothers. It is also common for Malay women to not only perform their duties in the private realm, but also to work alongside men in the public sphere as farmers or selling produce at markets and bazaars. These traditional roles of women in private and public spheres remain true in the modern times - Malay women still value their roles as wives and mothers while at the same time playing an extra role as career women. Indeed, fulfilling the domestic roles as mothers and wives are seen as religious obligations and women find it as a source of gratification (Saili, 2012). It is also important to note that marriage is regarded as an ibadah in Islamic teachings and the only legitimate way of fulfilling human needs (fitrah) for sexual intimacy and procreation. In this regard marriage and family is not only important in maintaining social structure but also a means towards achieving the status of a pious Muslim.

Having said the above, it is apparent that women who do not marry past marriageable age are considered as unusual. Their roles as Malay women are regarded as anomalous and their femininity flawed. They can easily become suspects to illicit sexual activities because they do not have legitimate sexual partners or husbands (Ibrahim \& Hassan, 2009; Vignato, 2012). Never-married women are being labelled as 'andartu' (in short for 'anak dara tua' or literally translated as 'old virgin' in English language) and are portrayed with negative stereotypes as if 'something is wrong' with them. However, recent trend that shows rising number of never married successful professional women managed to relax these negative stereotypes but do not totally erase them. Singleness amongst women is still seen as 'a problem' that needs to be resolved by way of marriage. Jones (2004) reported that the announcement of the rising number of unmarried women in 2000 had prompted many lively debates by religious figures, Malaysian press as well as discussions at the parliament. This is also the case in late 2005 when Utusan Malaysia, one of the Malaysian Malay language mainstream newspapers, reported that $70 \%$ of unmarried Malaysian women are the professionals. Other articles that appeared in Utusan Malaysia Online 
(http://www.utusan.com.my) featured 'catchy' headlines like 'Menyelesai masalah jodoh wanita profesional' ('Solving the problems of unmarried professional women') (02.12.2005); 'Izin poligami, kurang anak dara tua' ('Allow polygamy, less spinsters') (21.08.2005); and 'Syor benarkan lelaki mengamalkan perkahwinan misyar' ('Suggestion to allow misyar marriages for men') (25.05.2006). These articles attracted massive response from the public leading to suggestions of promoting polygamy and misyar marriages to 'solve the problems of single professional women'. While polygamy refers to a man taking more than one wife (i.e. up to a maximum of four wives), misyar is a marriage arrangement where the husband is released from his responsibility to provide financially for his wife, with the consent of the wife. This arrangement is suggested for wealthy single women who can afford themselves financially but need a husband to fulfill their biological and sexual needs. The suggested solutions of polygamy and misyar marriages were responded differently by the newspaper readers that comprise mainly of the Malays. Some sectors of the Malay society agreed while others disagreed with the suggested solutions. However, what is more relevant to my discussion here is the reasons why singleness amongst women is considered as 'problematic'.

From my reviews of the articles that appear in the Malaysian Malay mass media regarding singleness among women, I gathered four main reasons for this 'problem'. Firstly, late marriage for a woman is seen as affecting fertility rate and lowers the chances of having many children; thus contributing to the decline of the Malay population. For the Malays, children are considered as God's gift (rezeki) and should be cherished by all married couples. Children are hoped to take care of their parents when they grow old. Thus, for unmarried individuals concern arises over old age care. Secondly, prolonged singleness is seen as a social change that challenges long-accepted norms of universal marriage among the Malays. Traditionally, the roles of a woman are defined according to her lifecycle beginning from being a daughter and later a wife, mother and grandmother. If a woman remains unmarried, her role as a daughter continues and thus indicates her parents' unfulfilled responsibility of finding her a suitor. In traditional times having an unmarried daughter is regarded as a misfortune and disgrace to the parents because they are afraid that she might get involved in extramarital sexual activities. This is illustrated in the Malay saying 'looking after a group of cattle is easier than taking care of one daughter' ('menjaga lembu sekandang lebih mudah dari menjaga seorang anak perempuan'). This concern over unmarried daughters remains till contemporary period. However parents nowadays are more trusting in their daughters as many of them left parental homes early to pursue higher education and taking the opportunities in the job market.

The third problem relates to female biological needs for sex. Since sex outside marriage is prohibited in Islam, being single should also means having no sex partners. Single women are seen to be open to possibilities of getting involved in illicit sexual activities and this is often voiced by religious authorities as well as married women. They claim that unmarried women are lonely and might seek companionship with married men, thus becoming threats to other people's husband. Fourthly, the 'problem' of singleness is seen as a challenge towards marriage institution. There are concerns that unmarried women are rejecting marriage because it hinders their freedom and possibilities that unmarried women are opting for alternative lifestyles such as cohabitation, lesbianism and lifetime celibacy.

Further reviews of literature on singleness amongst Malay women reveal that there is a lag of academic studies in this topic which is often debated in the mass media. Also, more often than not, these discussions are dominated by religious figures who are mostly men or married women. The voices of single women themselves are often silenced or taken for granted. This is also related to the fact that not many women would want to talk about their singleness and considered it as a sensitive topic. Realising this, it is the aim of my study to fill up the gap in understanding singlehood from the perspectives of single women themselves. Fortunately, as a single woman myself, I had the opportunity to listen to their voices as they open up and share their stories.

\section{This Paper}

As stated earlier, this paper is based on narratives of three women who feels that 'something is wrong' with them. Participation in this research is based on voluntary basis. The criteria of women included in my study are (1) over 30 years old and (2) never been married. The cut-off age of 30 as the lower limit was chosen because 'the age-thirty transition' factor. Stein (1992) suggests that the period during late twenties and early thirties is a time when singles might experience confusion and struggle with societal pressures, families and themselves. They might start to re-evaluate their goals and values in work, thinking of their living conditions and possibilities of getting married. Adding to this, Adams (1976, p. 11) argues that at the age between twenty-five and thirty, 'the matrimonial mart is at its busiest' leaving those who do not follow this path with smaller social circle and companionship. More importantly, at the age of 30, the biological fact that women's fertility rate starts to dwindle confronted single women with difficult situation regarding marriage and singleness. Finally, at the age 
of 30 , most single women already achieved some economic solidarity hence the need to marry for economic security ceases to be a pressing priority.

The second criterion i.e. 'never been married' is important here due to the many notions of singleness as indicated in the Malay language. As mentioned earlier the Malay term for never married women who have past marriageable age is 'andartu'. For single again women, two Malay terms are used to represent them i.e. 'janda' for divorcees and 'balu' for widows. Current development in gender awareness in Malaysia resulted in a new terminology that groups these two categories as 'ibu tunggal' or 'single mothers'. 'Ibu tunggal' is a positive notion as compared to the term ' janda' because it indicates the image of a respectable mother who carries her responsibility alone without a husband. As for 'andartu', the 'softer' word for it is 'andalusia' or 'anak dara lanjut usia' ('over the age virgin'). Unfortunately the new term still carries negative connotation and the preferred term remains 'andartu'. The point that I wish to highlight here is that the notion of singleness for the Malays is closely related to these different categories of singles. Consequently each category is perceived differently by the society, hence different experiences of singleness by ever married and never married women. In this regard I agree with Byrne's (2004) and Meenakshi Thapan (2003) arguments that parenthood is a claim to adulthood and other responsibilities and privileges that come with it. Furthermore, past experiences of marriage or parenthood will influence one's narratives of the self and thus their identity construction. With all the reasons stated above, my study exclude the once married category and only concentrated on never married singles.

The participants of my study were recruited through personal contacts and 'snowballing method'. Participants were interviewed and each interview took one to two hours. Interviews were audio recorded (with the consent of the participants), and later transcribed verbatim. The interviews were informal, and though a guide was prepared, participants were allowed to express their views freely and were only probed with questions for clarification. The transcripts were then analysed to determine patterns and themes that are salient to their experience of singleness. In this paper I shall be focusing on three participants that shared their feelings of inadequacy as single women by posing the question of 'what is wrong with me?'. The three participants were given pseudonyms to protect their privacies. Below are their stories.

\section{The Stories of Three Women}

\subsection{Suzie's Story: Inability to Build Relationship That Ends in Marriage}

Suzie is a lecturer and was in her late 40's when I interviewed her. Suzie is the fourth daughter of seven siblings. Three of her elder siblings are married while others are still single. One of her younger sisters is a divorcee after being married for only nine months. Suzie lives alone at her own apartment which is located near the university where she works. Suzie described herself as friendly and approachable and having good relationship with her family members. When she was younger, she never thought that she will remain single up to her late forties. With regard to having potential suitors, Suzie commented:

"I've been having strings of boyfriends, off and on, over the years... So, it's like, I can see the pattern... urm... you get to know someone, you know... but it doesn't materialised in the long run. So it makes me feel like what is wrong with me? What is wrong with me?... Am I too... urm... educated that they don't want to talk to me, or they don't want to make me a wife? Am I too much of a talker or am I making them feel intimidated or that kind of things..."

Besides pondering on her characters that might shy men away, Suzie said that she is always critical about her looks and physical appearance. She takes the effort to dress nicely and look presentable. She also watches her weight and eats healthily. On another note, Suzie related her inability to forge matrimonial relationship with black magic:

"Yea... perhaps there are bad things happening... you know... me, being an Asian... definitely I will look at certain spiritual thing, and I got feedback saying that... urm... saying that I and all my family members have got some kind of voodoo charm thing, you know... where people are jealous of my family and they have done something to my family so urm... u know, men will look at you not as something nice and appealing... they see you like a piece of cloth, wreck... I can see the pattern and the same thing happens with my other sisters... You know, it's difficult to meet men."

However, Suzie said that she can never be sure if those bad omens and voodoo are the actual reasons for her inability to get married. Being an educated person it is difficult to believe that these things are happening, but she just cannot stop thinking of the possibility. Suzie still hopes that one day she will meet her jodoh (Note 3) despite accepting the fact that it's getting harder and harder as she grows older. However she does not seek actively for potential mates and leave it to God to grant her jodoh. In the meantime, Suzie focuses on her career because, 
"This is my life. What else do I have but this, so I decide to concentrate on my career". Suzie spends most of her time at the office and stays focus with her career advancement.

\subsection{Aziah's Story: Incomplete Due to Not Having Her Own Children}

"I have always thought that my ideal life should consist of a family. I mean having a husband and children. Also, my career and my office", said Aziah, a 42 year old lawyer who runs her own legal firm. Aziah is proud of her achievement in terms of career, "If we measure success in terms of what we can buy, I mean the material aspect... I guess in terms of work, I am very happy with where I am right now. I have achieved what I wanted. Well, I have achieved more that I've set. So, yes, I am successful in terms of my career."

However, in terms of her dream of having her own family, Aziah did feel that she is not achieving what she had always wanted. She is happy that her relationship with other family members is very close and she always lends a helping hand whenever her married sister and brother need her to look after their children. Aziah enjoys looking after her nephew and nieces and wishes that she will have her own children:

"Because you know... when you start taking care of the children, I will start thinking, what if... what if I have my own children? But does that bother me? I will be lying if I said it doesn't bother me at all. Does it make me sad? I will be lying if I said it doesn't. But what matters is how long will I feel that way? I will not let that affects my life, no! I will not let the question of 'what is wrong with me?'... yeah, that makes me sad but you just have to be strong. I've got to control my emotions."

From her tone, I could tell that she was really sad when she related her story. Further into the conversation, Aziah told me about an occasion when she felt really hurt by a remark from one of her acquaintances:

"I'll be 42 soon... yeah... friends do make remarks, but whether I want to make that remarks affects me or not. It hurts... at that point... Ok, I will tell you the exact words - "Who would want to marry you? You are approaching menopause?". She may or may not have the intention to hurt me. There were a couple of others when she said that... They knew that it may or may not be sensitive, but some friends just don't care! All right... but I don't know why I was affected by that. I didn't say anything... But it affected me so much that when I went home, I was praying and crying thinking about it."

For Aziah, that occasion made her re-think about the purpose of her wanting to be in marriage. She started to see a different perspective and accepted the fact that she might not end up having her own children after all. However she still hopes to eventually get married because she needs a companion more than anything else. Aziah said that, "I think I feel better now that I have accepted the fact that marriage might not give me children of my own. I now see marriage as important for companionship... having a husband to share my live with."

\subsection{Mimi's Story: Single Status as a Lower Social Standing}

Similar to Suzie, Mimi shared the view that smart women might not be attractive to men. She said, "I guess sometimes we have to act dumb so that men will think that they are smarter than us. Yeah, that will boost their ego. Maybe that will make us look more feminine and they will be attracted to us." Mimi also relates femininity with looking good, being soft spoken and having domestic skills especially cooking. Mimi's concern over femininity is more related to the fact that she is working in a male dominated industry - she is an entrepreneur and runs her family business. This 33 year old lady finds it very challenging to be a woman, what more a single woman, when most of her clients and business partners are married men. She feels that being married will enhance her status and help her gain respect and be treated more seriously by others. Mimi views marriage as important not only for herself but also for her family, "Marriage is not all about me. If I am single, I might be open to fitnah (gossip) and that won't be good for my family and my business. Being single does not mean complete freedom, I do have limitations because I carry my family's good name and our business image".

Mimi said that she became aware of the need to get married when her younger brother told her that he is getting married. Mimi was shaken by the news and started to think about herself and what will become of her:

"As a single, I do feel lonely at times. Sometimes I feel inadequate. I think that I am not up to the standard that men do not want me. People around me don't ask why I am not married yet. But I feel that something seems wrong with me. As if I am late for something. I was 26 years old then, still young I would say. Nevertheless I felt that I was missing something. I was afraid of what people might call me. You know... in our society if we are not married, we are labelled with all sorts of names."

However Mimi did not allow negative feelings to take the best of her and thus turns her worries and loneliness into a mission that she wishes to accomplish. Indeed, her brother's marriage was a turning point for Mimi to redefine her vision and mission in life. She knew that she wanted to get married and have her own family but she 
also knows that jodoh is in God's hands and she can only pray for the best. Nevertheless Mimi took actions to improve her outlook about marriage and seek opportunities to meet new people in search of potential suitors. She holds the view that as singles, she has to be positive and happy because "positive and happy singles will eventually make better wives". As such, Mimi started to practice better communication skills and even enrolled in a postgraduate degree programme in order to get to meet new people. On top of that business remains Mimi's priority and she strives to achieve financial independence so as to be prepared for the worse - i.e. if she is fated to stay single forever then she will have enough money to face old age without the support of children and husband.

\section{Conclusion}

This paper discusses the experiences of inadequacy among single women who misses the marriage transition and poses the question of 'what is wrong with me?'. The reasons why these women feel inadequate or incomplete are illustrated by the stories of three women who volunteered to share insights into their lives as unmarried women past marriageable age. Bearing in mind the societal perceptions towards the unmarried, their concerns are certainly not unfounded. This can be related to Holden's (2007) assertion that 'the meaning of singleness are in dialogue with the meaning of marriage, with each category shifting in relation to the other in response to wider societal change'. Between the two, the dominant category i.e. 'marriage' is perceived as the positive category where the 'single' category be compared to. Consequently, the category 'single' is perceived as negative in contrast to the positive category of 'marriage'. Reynolds (2008:14) shares the same view by asserting that singleness is often discussed in terms of 'otherness' or 'by stating what single woman is not: not sexual, not married, not a parent, not living with a partner'. My study on single women's feelings of inadequacy agrees with Holden's and Reynold's statements. The three factors highlighted in the stories of the three single women above reflect that their feelings of inadequacy are very much related to 'what they do not have' in comparison to married women. The first two factors i.e. inability to forge relationship that ends in marriage and worries of not having their own children can be linked to the roles of marriage in fulfilling human fitrah (nature) towards sexual intimacy and procreation. The third factor i.e. concern that single status is of lower social standing relates to the role of marriage in upholding social structure. I suggest that the centrality of marriage in understanding singleness amongst women lies in the fact that women's roles are defined within the natural vocation of women as wives and mothers. However it is also important to note that though singles missed the marriage transition into adulthood, single women who have successfully managed their experiences of inadequacy do live fulfilling adult lives by having close relationships with friends and family members, committed towards self-improvement and being professional at work.

\section{References}

Adams, M. (1976). Single Blessedness: Observations on the Single Status in Married Society. New York: Basic Books Inc. Publisher.

Azmawati, A. A., Hashim, I. H. M., \& Endut, N. (2015). "Don't marry, be happy!" - How single women in Malaysia view marriage. SHS Web of Conference 18, 03001 (2015). http://dx.doi.org/10.1051/shsconf/2015 1803001

Byrne, A. (2000). Single Women's Identities in Contemporary Irish Society (Ph.D Thesis). Department of Political Science Sociology, University College Galway, Ireland.

De Paolo, B. (2006). Singled Out: How Singles are Stereotyped, Stigmatised, and Ignored, and Still Lived Happily Ever After. New York: St. Martin's Press.

Holden, K. (2007). The Shadow of Marriage: Singleness in England 1914-60. Manchester: Manchester University Press.

Ibrahim, R., \& Hassan, Z. (2009). Understanding singlehood from the experiences of never married Malay Muslim women in Malaysia: Some preliminary findings. European Journal of Social Sciences, 8(3), 395-405.

Jones, G. (2004). Not 'when to marry' but 'whether to marry': the changing context of marriage decisions in East and Southeast Asia. In G. Jones, \& K. Ramdas (Eds.), (Un)tying the knot: ideal and reality in Asian marriage. National University of Singapore: Asia Research Institute.

McCall, G. J., \& Simmons, J. L. (1978). Identities and Interactions: An Examination of Human Associations in Everyday Life (Revised Edition). New York: The Free Press.

Omar, R. (1994). The Malay Woman in the Body: Between Biology and Culture. Kuala Lumpur: Penerbit Fajar 
Bakti.

Peng, T. N. (2007). Trends in delayed and non-marriage in Peninsular Malaysia. Asian Population Studies, 3(3), 243-261. http://dx.doi.org/10.1080/17441730701746391

Reynolds, J. (2008). The Single Woman: A Discursive Investigation. London \& New York: Routledge.

Saili, J. (2012). Life Experiences of Single Professional Malay Muslim Women: An Exploration of Psychosocial Cultural Issues (PhD Thesis). Curtin University of Technology, Australia.

Stein, P. J. (1992). The diverse worlds of single adults. In J. M. Henslin (Ed.), Marriage and Family in a Changing Society (4th ed.). New York: The Free Press.

Thapan, M. (2003). Marriage, well-being, and agency among women. Gender \& Development, 11(2), 77-84. http://dx.doi.org/10.1080/741954320

Trimberger, E. K. (2005). The New Single Woman. Boston: Beacon Press.

Vignato, S. (2012). "Men come in, men go out": Single Muslim women in Malaysia and Aceh. Social Identities Journal of the Study of Race, Nation and Culture, 18(2), 239-257. http://dx.doi.org/10.1080/13504630.2012. 652847

\section{Notes}

Note 1. Malaysia is a multiethnic country with a total population of over 26 million. Major ethnic groups are Malays (50.3\%), Chinese (23.8\%), non-Malay indigenous people (11.0\%) and Indians (7.1\%). The official language is Bahasa Melayu. However other languages such as English, Chinese, Tamil and Punjabi are also spoken. The official religion is Islam which is practiced by about $60 \%$ of the population. The rest of the population practices other religions freely. It is also important to note that the Federal Constitution stipulated that Malays are by definition Muslims. (Women of the World: Laws and Policies Affecting Their Reproductive Lives - East and Southeast Asia 2005. Center for Reproductive Rights, Asian-Pacific Resource and Research Center for Women, ARROW).

Note 2. The Malay terminology for never married males past marriageable age is 'bujang terlajak' (literally translated as 'unintentionally over the age singles'). Contrary to 'andartu', 'bujang terlajak' carries lesser negative connotation. Also, singleness amongst men is seldom discussed among the people or by the Malay language mass media.

Note 3. 'Jodoh' is a Malay term for soul mate that comes from God at perfect timing. Malays believe that matters of life and death and that of meeting one's soul mate is in the hands of God. Those who are not married are said to have yet to meet their 'jodoh', while those who are divorced or widowed are said as having reached the end of their 'jodoh'.

\section{Copyrights}

Copyright for this article is retained by the author(s), with first publication rights granted to the journal.

This is an open-access article distributed under the terms and conditions of the Creative Commons Attribution license (http://creativecommons.org/licenses/by/4.0/). 